[Manuscript draft. Final version accepted at Perspectives on Science, special issue on Severe Uncertainties in Science, Medicine, and Technology, eds. Mattia Andreoletti, Daniele Chiffi, \& Behnam Taebi]

\title{
Moral Uncertainty in Technomoral Change: Bridging the Explanatory Gap
}

Philip J. Nickel (Eindhoven University of Technology), Olya Kudina (TU Delft), and Ibo van de Poel (TU Delft)

Correspondence: p.j.nickel@tue.nl

\begin{abstract}
(98 words)
This paper explores the role of moral uncertainty in explaining the morally disruptive character of new technologies. We argue that existing accounts of technomoral change do not fully explain its disruptiveness. This explanatory gap can be bridged by examining the epistemic dimensions of technomoral change, focusing on moral uncertainty and inquiry. To develop this account, we examine three historical cases: the introduction of the early pregnancy test, the contraception pill, and brain death. The resulting account highlights what we call "differential disruption" and provides a resource for fields such as technology assessment, ethics of technology, and responsible innovation.
\end{abstract}

Keywords: moral inquiry, moral uncertainty, technomoral change, disruption

\section{Short biographies of the authors:}

Philip J. Nickel is an associate professor of Philosophy and Ethics at Eindhoven University of Technology. His current research explores how epistemology provides insight into applied ethics, and vice versa. He has written a number of articles about trust and testimonial reliance.

Olya Kudina is a postdoctoral researcher exploring the technologically induced value change from a pragmatist perspective. She works at the intersection of moral hermeneutics, (post)phenomenology, bioethics and design. Currently, Olya explores the case of Al-based voice assistants and how they change our values of socialization, good parenting and privacy.

Ibo van de Poel is professor in ethics and technology and head of the department Values, Technology and Innovation at TU Delft. His research interests include design for values, responsible innovation, moral responsibility in research networks, ethics of newly emerging technologies, new technologies as social experiment, and value and moral change.

\section{Introduction}

Technology and moral values influence one another in a process of technomoral change (Swierstra, Stemerding and Boenink 2009; Wright et al 2014, vol. 87; Arnaldi 2018, vol. 12). The introduction of the birth control pill, for example, is said to have caused a shift toward more social permissiveness about sex outside of marriage and homosexuality (Swierstra, 
Stemerding and Boenink 2009, p. 132n). According to the theory of technomoral change, values, principles, and judgments are mediated and ultimately changed by the introduction of such technologies on three levels: general values such as privacy and reproductive autonomy; mid-level principles such as the right of access to contraception; and specific moral judgments made by people in concrete situations, such as the decision to start using the birth control pill or to approve of somebody who is having sex outside of matrimony. When the birth control pill leads to sex for pleasure being celebrated, values of reproductive autonomy, sexual autonomy, and privacy take the place of chastity and fidelity within public discourse about sexual morality. Such changes in general values ripple through individual judgments made by millions of people, leaving visible traces of deliberation, both public and private.

In its present form, the theory of technomoral change faces an explanatory gap. One of the most ethically salient and historically interesting things about technomoral change is its sometimes disruptive character: the powerful disagreement and confusion it unleashes within social discourse. The objects of technomoral disruption are the individual and social moral norms operating at the levels of values, principles, and judgments. These are what sometimes get disrupted in technomoral change. However, a full explanation of disruption needs to do more than point to changes at these levels and the kinds of controversies that attend them. Although some forms of moral change, such as the shift in sexual mores, are revolutionary, others happen calmly, as if through seamless social contagion. Current theories of technomoral change do not clearly mark this distinction. If the theory of technomoral change could offer a robust characterization of technomoral disruption, distinguishing what it is about some technologies that leads to various disruptive effects in society and what properties of individuals and social groups are associated with these differentially disruptive effects, this would provide a conceptual resource for fields such as technology assessment, ethics of technology, and responsible research and innovation.

We argue that this explanatory gap can begin to be bridged by looking at the epistemic and deliberative dimensions of technomoral change. We single out two phenomena of special relevance to moral disruption: moral uncertainty and moral inquiry. In moral uncertainty, there is a point during the transition from one set of moral values to another, in which some or all members of a relevant social group are uncertain which values should be applied, and how. This could manifest itself at any of the three levels identified above: values, mid-level principles, or specific moral judgments. Moral uncertainty contains the seeds of disruption because it is often experienced as unpleasant, hazardous, and undermining of moral agency. Uncertainty will typically start individually but it can also become collective if an entire group, e.g., of practitioners, becomes uncertain about what values to apply or how to apply them. It undermines ordinary grounds for action, including everyday ways that individuals and groups enjoy and contribute to standing social and material arrangements. In moral inquiry, as we use the term, the social group as a whole is engaged in conflicting and sometimes antagonistic discourse, exhibiting collective perplexity about moral values, principles, and judgments. On our approach, when "the pill" causes chastity and sexual fidelity to give way to privacy and reproductive autonomy, its disruptive character is manifested in individual or collective uncertainty and perplexed public inquiry about the relevance, priority, and correct application of these values. 
Moral uncertainty concerns the moral interpretation of experience: when do individuals and groups take states of affairs to imply that particular moral attitudes, such as blame, guilt, trust, and attributions of authority and responsibility, are apt? Sometimes it arises because we do not know which of our existing moral concepts apply, and at other times because of a conceptual gap in which we have not yet invented or encountered the moral concepts that would help us interpret our experience and contribute to shared collective practices, an idea similar to Fricker's notion of "hermeneutical" epistemic injustice (2007). In still other cases, it arises because "thick" descriptive concepts such as pregnant or dead are reinterpreted, as we will see in Section III.

By developing an account of moral uncertainty and moral inquiry in relation to technomoral change, in this paper we work toward a more complete account of disruption. Looking at three historical cases, we gain insight into the distinctive epistemic and deliberative processes surrounding technomoral disruption, foregrounding the nuanced dynamics of technomoral change.

\section{Current theory of technomoral change}

Swierstra, Stemerding, and Boenink have developed a theory of how new and emerging science and technology ("NEST") change ethical values, in terms of moral routines that are disturbed (2009). It has been applied to a number of NEST technologies and amended so as to incorporate other ethical concepts such as responsibility (Arnaldi 2018, vol. 12). The theory was developed to be anticipatory: it helps formulate plausible scenarios for reflection about the desirability of future technologies. According to this theory, "We constantly see NEST uprooting established moral routines. These disturbances manifest themselves as controversies about how to re-establish a fit between NEST, our moral world, and us. [For example,] the pill could uproot traditional sexual morals by providing women with the technological means to actually practice their sexual autonomy" (Swierstra, Stemerding, and Boenink, 2009, p. 120). The "disturbances" and "controversies" wrought by NEST are one of the key phenomena the authors wish to anticipate. Understanding this morally disruptive potential of technology is important to the assessment of new technologies, and forms the basis of social learning about the mutual influence of technology and society (ibid., p. 120).

According to NEST ethics, morality and ethics play distinct roles. Morality is normally a matter of unconscious routine; we only start to notice it when there is a violation of moral norms, when two moral routines conflict with one another, or when it fails to deal satisfactorily with "new problems" (ibid., p. 123; see also Swierstra 2013, 15: 206). Ethics, by contrast, is a matter of controversy, dealing with cases where morality must be reassessed, discussed, and reflected upon. Technology disrupts "cool" moral routines in such a way that they become the subject of "hot" ethical discourse (ibid.). "[T]echnology destabilizes moral routines, which then provokes ethical reflection and discussion, which then do or do not result in new ethical answers that re-stabilize into new moral routines" (Swierstra 2013, 15: 203). This theory of the disruption of routines, originally traced to Dewey (ibid., p. 206), has been adopted by others using the NEST ethics approach (Arnaldi 2018, vol. 12).

We have three worries about this account of the disruption of moral routines. The first is that moral routines can change without being disrupted. Imagine a hypothetical world where in 
one year, birth control pills are not available and people are urged to be chaste and faithful, and in the next year, the pill becomes available, and people celebrate reproductive autonomy. In this imaginary world, the change happens in such a way that people simply adjust to a new way of doing things and a new way of talking. Although the two routines are incompatible with one another, and although there is a "habituation" period as people move from one moral routine to another, this is like the adjustment of moving from the country to the city, or from one country to another, adjusting to a new way of doing things. In this hypothetical scenario, changing moral routines is difficult only insofar as one needs to break old habits, which famously die hard. But surely this is not an explanation of moral disruption, as if it were simply a change of routines. Why do some changes of moral routines lead to "hot" discourse and intense discussion, while others do not?

The second worry is that moral disruption can occur even when there is no change in our moral routines. Suppose a new technology, for example a quantum computer or a chip that allows the selection of characteristics for one's offspring (Kudina 2019, vol. 16), becomes scientifically and instrumentally possible but has never actually been used. Such developments could have morally disruptive effects due to the mere fact of their possibility, even before they have caused a change to moral routines. The uncanny prospects of a scientific breakthrough might even so unsettle people that they cling even more fiercely to their current values and routines, in ways that have unexpected effects elsewhere. It seems, then, that the change of moral routines does not explain the disruptive potential of technology for moral values. While Swierstra leaves it open that some "hot" discourse "do[es] not result in new ethical answers that re-stabilize into new moral routines" (2013, 203), this could refer either to a stubborn reversion to old routines, or to a persistent impasse. It is important to leave room to distinguish these very different possibilities.

The last worry concerns the dynamics and complexity of moral change. The focus on a single process of transition between routines draws our attention away from some of the more fragmented ways in which technologies contribute to moral change and disruption. For example, moral routines may emerge as a result of technological innovation without adapting or directly replacing previous routines. The introduction of the augmented-reality device Google Glass was accompanied by new sociotechnical practices that did not fit the dominant definition of privacy as control of information (Kudina and Verbeek 2019, vol. 44). This resulted in emergent parallel conceptions of privacy with different ramifications (e.g., for experience and memory-making, being in public, communication and identity building). Processes that lead to emergent, parallel moral communities can turn disruptive when no common set of norms can readily be found for purposes of regulation and conflict resolution, creating ambiguity and discord about what shared value framework to apply. In such a case, a common societal transition from one routine to another is evidently not what causes disruption.

These three worries point toward an explanatory gap in the theory of technomoral change. Moral change and disruption are not fully explained by a change of moral routines. While these worries do not by themselves frame a new taxonomy of technomoral disruption or an encompassing account of value change, they destabilize confidence in the central element of the NEST ethics account as a complete picture. Swierstra et al. suggest that controversies and debate underpin technomoral change and provide a detailed taxonomy of argumentation in such controversies (2009), but this leaves much room for interpretation 
regarding the nature and dynamics of moral disruption. In order to anticipate the impact of new technologies - one of the core ambitions of NEST ethics - we need to close this explanatory gap. By pinpointing the causes of disturbances and controversies wrought by new technologies with greater precision, we can more adequately anticipate their impact and promote enlightened societal discourse around them. This is why we find it important to take a second look at processes of moral disruption, and to identify concepts that do more to illuminate them.

Scholarship in other fields provides clues, but they are not as easy to follow as one might hope. In the last 25 years, there has been substantial discussion of both the "evolution of norms" and of "moral revolutions." On both topics, cases of value change are discussed, including the evolution of norms for smoking cigarettes in public (McAdams 1997, vol. 96), and the abandonment of foot binding in China in the Nineteenth Century (Appiah 2010).

In the literature on the evolution of norms, one finds relatively few ideas that help understand moral disruption. Scholars in this field often focus on the mechanisms by which norms are "naturally selected" as optimizing or satisficing. Norms are sometimes destabilized by changing external conditions (Bicchieri 2005), but the idea that there is an "invisible hand" that guides social norms in the form of behavioral incentives for different strategies of interaction does not leave room for much confusion, uncertainty, or disruption. When the incentives change, the norm changes - disruption, such as it is, consists simply in abandoning one way of doing things for another.

Recent work on moral revolutions proves more promising. Baker (2019) gives an account of moral disruption as moral revolution. He explicitly parallels Kuhn's account of scientific revolutions. Baker's account is of particular relevance to the explanatory gap because he distinguishes moral revolutions, moral reform, and moral drift as different varieties of moral change. Revolutions are characterized by paradigm change, whereas reform and drift are not. By giving a distinct characterization of moral revolutions, Baker responds to the need to distinguish between disruption and technomoral change.

Baker's model of revolutions differs from Kuhn's in two important ways, however. The first is its emphasis on the role of dissidents, those who "attempt to renegotiate the terms of cooperation in an established morality" (2019, p. 18). Baker defines moral revolution and reform, as contrasted with moral drift, in terms of the intervention of reformers. By giving this defining role to dissidents and reformers, disruptive moral changes are portrayed as essentially agent-driven processes whose aim is intentionally to modify or displace the extant moral paradigm (ibid., p. 27). In this way, Baker downplays the influence of social, technological and economic factors that co-produce moral revolutions. One of Baker's own examples is women's demand for access to public latrines in Nineteenth Century Britain, which violated Victorian norms of femininity. By essentializing the role of dissident women's advocacy groups, Baker pushes emergent socioeconomic processes and technological development, such as the invention and popularization of the flushing toilet itself, to the background. Within Kuhn's account of scientific revolutions, by contrast, dissidents, reformers, and revolutionaries hardly play a role. Scientists play their part, individually and collectively, but processes such as discovery and the appearance of irresolvable problems are the focus of Kuhn's analysis. 
The second way in which Baker's model differs from Kuhn's is that it is not focused on epistemic factors. On Kuhn's account, "the emergence of new theories is generally preceded by a period of pronounced professional insecurity. As one might expect, that insecurity is generated by the persistent failure of the puzzles of normal science to come out as they should" (1962, pp. 67-68). Scientists become perplexed when they come to recognize that their paradigm is not adequately dealing with standard problems. Baker, by contrast, emphasizes the role of conflict and social struggle, rather than perplexity and uncertainty, in bringing about moral revolutions. ${ }^{1}$ They are the outcome of an agonistic conflict of social interests, rather than the resolution of puzzles causing confusion and perplexity for individuals. $^{2}$

On both points, our account will shift away from Baker's. First, we give a strong role to both technological and socioeconomic factors in the production and resolution of moral disruption. We see these factors as producing difficult situations that individuals are called upon to resolve by improvising on the moral repertoire they currently have available. Second, following Kuhn, we highlight the epistemic dimension of moral disruption. We hypothesize that this takes the form of uncertainty and perplexed inquiry about the legitimacy, weight and scope of application of existing moral values and norms.

\section{Moral change, uncertainty, and inquiry: three cases}

In this section we explore three historical cases that illustrate how epistemic concepts of moral uncertainty and moral inquiry can enrich our understanding of moral disruption in technomoral change. These cases have been selected based on available source materials and previous discussions in the literature on technomoral change. ${ }^{3}$ Moreover, they point to how seemingly everyday technologies can be disruptive: each of our cases has been described as a revolution without initially getting much public or media attention.

We interpret these cases at an individual or "localized" level in terms of moral uncertainty and at a societal level in terms of moral inquiry. At the localized level, we find statements of moral uncertainty expressed in personal interviews, oral histories, and accounts of

\footnotetext{
${ }^{1}$ Hermann's (2019, vol. 32) account of moral progress is both less agent-driven and more epistemic than Baker's account of moral revolutions. While acknowledging the propelling role of individual moral dissidents, it makes overall moral progress conditional on socioeconomic factors that bring about a collective change of judgment. Hermann's account does not address moral disruption or moral revolutions, however.
}

${ }^{2}$ One way of giving an epistemic spin to the theory of moral revolutions is to interpret moral emotions epistemically. Threats to established moral paradigms might have a characteristic epistemic signature. Appiah (2010), for example, focuses on the virtue of honor as a mechanism of moral revolutions. For Appiah, appeals to rationality and morality alone do not typically succeed in fomenting revolt against an established tradition. Once traditional practices start conflicting with a sense of honor (individual, group or national), change is inevitable. On this account, threats to honor could be taken as epistemic signals of the need for a new paradigm. However, as Appiah himself recognizes, the virtue of honor has largely fallen out of public discourse.

${ }^{3}$ The reader should be aware that the three worries about the NEST ethics account from Section II do not structure the case analysis. 
conversations. At a societal level, we see moral uncertainty and moral inquiry expressed in shifting and conflicting adoption of (tentative) positions in public discourse in newspapers and professional fora. Traces at both levels offer insight into the dynamics of moral change. They help locate how people, individually and collectively, give meaning to their experiences as moral agents trying to shape and respond to technology.

We wish to see what an epistemic reading of these cases can tell us about the dynamics of moral disruption: who is uncertain, what their uncertainty is about, and when this uncertainty begins and ends in relation to the adoption of the technology. In this way we might bridge the explanatory gap, going beyond the NEST ethics account without reducing the distinctively moral dimension of disruption to something non-moral (e.g., a power struggle).

\section{A. Early Pregnancy Test}

The introduction of the early pregnancy test (EPT) in the late 1970s has been described as a "private revolution" (Leavitt 2006, vol. 80). Prior to the EPT's development, women could medically verify a pregnancy by having a doctor carry out a blood test. The EPT, by contrast, required neither a visit to the hospital nor a physician to interpret the result. ${ }^{4}$ It may be tempting to read the case as a direct example of the NEST ethics framework, in which EPT changed moral routines surrounding reproduction. Indeed, the EPT shifted the purview in matters of pregnancy from the physician to the individual, thereby increasing the autonomy of prospective parents - especially women. However, our understanding of the disruption of the EPT is deepened by looking at the moral uncertainty and inquiry that accompanied changing discourse about the reproductive rights of women. This uncertainty and inquiry led to a reinterpretation of descriptive and normative concepts concerning pregnancy.

Firstly, the EPT promoted the demedicalization of pregnancy, enabling an expecting couple to assume parental responsibilities much earlier (Schadler 2013, vol. 62). The test, which had good reliability, was carried out in the privacy of one's home. This shift in the moment of verification of the pregnancy was perplexing but often valuable, as we can see in some accounts from the US National Institutes of Health survey of early EPT experiences in the 1980s and 1990s:

"I was hoping to become a happily married man with a kid. One morning I rolled out of bed and headed downstairs where my wife greeted me with a big smile and a home pregnancy tester wrapped in a bow. I didn't know she had purchased a tester, had never previously seen one and hadn't had my coffee yet. I didn't know what she was handing me. I looked at it, puzzled. I sniffed it. Slowly it dawned on me. 'Does this mean you're pregnant?' 'Yes,' my wife replied, somewhat flustered by my bizarre EPT sniffing behavior" (National Institutes of Health 2020).

This passage illustrates people's puzzlement about changes in matters related to pregnancy: in this case, the man did not expect that one could carry out such a test at home and find out about becoming a parent so soon. According to another early EPT user, "I always thought it was nice that we knew before my doctor did" (ibid.).

\footnotetext{
${ }^{4}$ Many women chose to verify the EPT result with a doctor (National Institutes of Health 2020).
} 
However, the mere possibility of the EPT caused a disruption in the medical community that contrasted with the enthusiasm of prospective parents. Doctors did not initially support the EPT, worrying that women would not be able to perform and interpret the test correctly. ${ }^{5}$ In a 1976 letter to the editor of the American Journal of Public Health, one practitioner wrote, "I feel that the reputations of both the commercial concerns and the profession of medical laboratory technology will suffer unless legislation is introduced to limit the use of such potentially dangerous kits [EPT]" (Entwistle, p. 1109). Thus, the EPT did not change pregnancy-related routines merely by introducing a quicker and earlier verification procedure, but it demedicalized this procedure and brought about a renegotiation of legitimate authority between expecting parent(s) and the medical community, whereby the former would no longer be conceived of as patients and the latter as gatekeepers of knowledge.

Secondly, in some cases, the EPT confronted expecting parent(s) with the choice of how to proceed with a pregnancy. Even though many women continued the practice of visiting a doctor about a pregnancy, they did so after their EPT result was already known and a decision had already been made about the pregnancy. Archival evidence indicates that most respondents took the EPT alone without telling anyone, made a decision about the result, and only afterward made the choice to inform someone (or not). The EPT was predominantly conceived as a means to relieve anxieties and confirm the suspicion of pregnancy: "The test... reduced by degrees my anxiety at not knowing - whether I wanted to be pregnant or not" (National Institutes of Health 2020). Another respondent reflects upon finding out about her unexpected pregnancy under undesirable circumstances and choosing to have an abortion: "I'm very grateful to live in an era where I can determine whether I'm pregnant privately and almost immediately, and have options to pursue regardless of the result" (Ibid.) Thus by enabling a private moment of discovery without external judgment, the EPT highlighted the decision-making capacity of a woman and gave her more options, regardless of whether or not she had a partner.

Thirdly, the EPT created new opportunities for women to exercise their reproductive rights, a development which in turn carried social repercussions for them. The EPT first needed to be purchased in a drugstore or at a family planning clinic. Consequently, women often came to confront the fact that that this "private little revolution" (Leavitt 2006, vol. 80) was not so private after all. The EPT came with a certain amount of stigmatization. Many health officials, advice books, and women's magazines at the time implied that EPT users were immoral, linking them with promiscuity and pregnancy outside of marriage (Ibid., 80:326-327, 335336). As an early EPT user recalls, "Right after graduation from college, I had to travel to an 'abortion clinic', complete with protesters out front, in order to get a pregnancy test. I didn't want to go to my own doctor for reasons of privacy" (National Institutes of Health 2020). Thus, while the test itself provided more privacy, women who purchased it were on public display and had to risk stigmatization and gossip for doing so. Consequently, many women travelled to different towns to buy an EPT in order to decrease the risk of being recognized. With the success of the female reproductive rights movement, over time the derogatory perception of women buying an EPT gradually changed to one in which women were celebrated for taking ownership of their bodies (Leavitt 2006, 80:327-328). The EPT thus

\footnotetext{
${ }^{5}$ This concern was somewhat warranted because of the complicated procedure and setup of the first EPTs (Leavitt 2006, vol. 80).
} 
played into the uncertainties provoked by the sexual revolution in the 1960 s and helped to materialize the reproductive rights and liberties of women.

The EPT case illustrates that what at first sight seems to be a change in routines accommodating the introduction of a technology in fact conceals multiple individual and collective moral uncertainties. It demonstrates how individual struggles to make sense of the early pregnancy results contributed to ambiguity at a societal level over the EPT, which materialized with resistance from the medical community and during the reproductive rights movement. In parallel, the introduction of the EPT provides a glimpse into the dynamics of descriptive and normative moral concepts around its use, such as the meaning of pregnancy and parenthood, and ideas about the proper role of women and the boundaries of reproductive rights. These elements can be used to expand on the NEST ethics account and more fully explain the moral complexities of EPT's introduction.

\section{B. The Pill and the Sexual Revolution}

Revolutionary language is also used to describe the effects of the birth control pill, one of the central examples in the literature on technomoral change (Swierstra 2013, vol. 15). The first type was approved by the United States Food and Drug Administration in 1960, giving American women the ability to prevent pregnancy much more easily and reliably. In many countries, such developments led to knock-on effects such as a steeper reduction of the birth rate (already in decline in previous decades), a reduction in the number of abortions, increasing use of abortion as a part of family planning rather than as a remedial measure, and sexual experimentation among adolescents (Ketting 2000, vol. 144 cited in Swierstra 2013, vol. 15). It played a key role in facilitating the "Sexual Revolution" (Marsh and Ronner 2008). This latter term designates a change in moral values surrounding sexual behavior in the late 1960s and 1970s, described by a contemporary observer as "more openness about sex and sex relations without strong emotional or romantic commitment" (Feldman 1969, $2: 55){ }^{6}$

Moral uncertainty about unmarried women's use of oral contraceptives was acute and explicit. American adolescents confronted with the possibility of using the pill were often vexed because it raised questions about their own attitudes toward the morality of casual sex (Cvetkovich et al. 1975, vol. 11). Students and faculty at a California public university expressed uncertainty whether it was right for campus health services to provide birth control to students, discussing the issue "quietly, seriously, but not unemotionally" (Randall 1969, 39:150). American university students and parents around this time period also expressed "confusion" about proper sexual behavior more generally, exhibiting "intense urgency" in their concerns (Farnsworth 1965, 35:676; 679). There is evidence that a similar situation was emerging in the United Kingdom (McCance and Hall 1972, 2:699).

Even the use of oral contraceptives by married women and those who already had children prompted controversy and moral inquiry among different populations over a significant period. Some physicians embraced oral contraceptives as soon as they became available, but others argued publicly that they did not constitute a medical treatment because they

\footnotetext{
6 The term "sexual revolution" has a history going back to the 1920 s and has often been coupled with the idea of a moral revolution, as documented in Martin (1996, vol. 25).
} 
were used for social reasons. This was connected with uncertainty about the authority of family planning clinics versus primary care physicians. ${ }^{7}$ The opinions of many Catholics softened in the 1960s, but others - especially those with more authority in the Church remained morally opposed to contraception even by married people (Greeley 1973, vol. 14). ${ }^{8}$ Women of color had a distinctive experience of birth control. Parry writes that "the legacy of white control over black sexuality during slavery as well as coercive and paternalistic practices in clinics fostered great distrust of birth control programs well into the late twentieth century. ... Yet black women also struggled against the pronatalist stance of black nationalist leaders in their efforts to gain access to family planning and control their own fertility" $(2013$, p. 7$)$. More broadly, the motives of those promoting the pill were called into question by their ties to the eugenics movement (Reed 1978).

As these accounts demonstrate, the moral disruption associated with the birth control pill urges us to examine the nature of the public debate and controversy, to engage identity politics and review the thick concepts we use to constitute a debate and who takes part in it. People experienced moral uncertainty at different times, and about different questions, in ways that depended on their identity and position in society. Moral uncertainty and inquiry appear to be the result of hermeneutic gaps and injustices elicited by the new technology (Fricker 2007). Women and physicians were forced to articulate views about their rights and authority in ways that their repertoire of existing moral concepts could not easily cover. They needed to improvise and expand this repertoire in response.

\section{Mechanical ventilators, organ transplantation and brain death}

One of the central moral revolutions described by Baker (2019) is the introduction of the notion of brain death in 1968, following the development of the mechanical ventilator in the early 1950s. The mechanical ventilator made it possible to pump air into patients' lungs so as to sustain heart activity. Some of these patients showed no brain activity, a fact that could be established through the application of EEG (Electroencephalography) technology originally developed in the 1930s. The notion of brain death helped to answer the question of how to deal with these comatose patients.

The new notion of brain death has also been linked to developments in organ transplantation (Giacomini 1997, vol. 44). The first successful kidney transplantation took place in 1954 (Machado 2007, p. 11), whereas heart transplantation did not occur until 1967 (Giacomini 1997, vol. 44). A redefinition of (brain) death was said to pave the way to their wider application. Keulartz et al. state that "While the norm that organs may only be removed once the donor is dead did not change, the definition of death was altered drastically. Accepting the new definition changed the practice: organs could now be removed from patients who

\footnotetext{
7 There is a long string of letters to the editor of the British Medical Journal on this topic. See, e.g., "The Contraceptive Pill," letter to the editor by Joseph William Dignan, The British Medical Journal 5281, March 24, 1962, pp. 878-879.

8 This controversy extended beyond Catholics, as the history of Loretta Lynn's hit single "The Pill" makes clear. Even in 1975, many country music stations refused to play the song, but it still became a top-5 hit. See Margaret Talbot, "Loretta Lynn's 'The Pill'," The New Yorker, 19 June 2018.

https://www.newyorker.com/recommends/listen/loretta-lynn-the-pill (accessed 26 May 2020).
} 
would previously not have been regarded as dead, without violating the norm" (2002, p. 16). Death proved to be a significant moral category for classifying permissible organ transplants.

As with the cases of the EPT and the pill, the moral disruption brought on by the new notion of brain death cannot be understood as the replacement of one moral routine by another. The passage just quoted suggests that the introduction of the notion of brain death caused a change in moral routines. However, an examination of the period of 10-15 years preceding this concept's introduction by the Ad Hoc Committee of the Harvard Medical School (1968, vol. 205) shows that it is more accurately described as the consolidation of a range of inquiries that had been going on since the early fifties and which were triggered by moral uncertainty about, e.g., how to deal with comatose patients who could be kept alive using a mechanical ventilator, and whether to allow transplantation in the case of such comatose patients. We witness this moral uncertainty at a more individual or localized level in the experiences of the neurologist C. Miller Fisher who in 1955 described comatose patients for whom "we had no language to describe them or rate them or anything ... the examination of the sick [comatose] patient was chaotic" (cited in Belkin 2003, 58:343). There are also clear signs of collective uncertainty. In 1957, anesthesiologists turned to Pope Pius XII for guidance on how to deal with comatose patients. At the world conference of anesthesiologists, the pope indeed raised the question, but declined to answer it, maintaining that "it remains for the doctor and especially the anesthesiologist, to give a clear and precise definition of 'death'" (cited in Baker 2019, p. 145).

There was uncertainty not only among medical professionals and theological authorities, but also among the media and the public. Two American newspapers drew opposing conclusions from the pope's statement, with one saying that doctors had the right to do everything possible to keep people alive even in dire situations where the heart had stopped beating, and another saying that they were permitted to withdraw artificial methods for reviving people in such situations (Giacomini 1997, 44: 1472). Strictly speaking, a relativist or liberal position could be imagined that permitted both of these options equally, but that is hardly what the pope could be taken to mean. Either way, both physicians and the public were clearly struggling to find some sort of guidance on the matter.

Their uncertainties were descriptive as well as normative (moral) in nature. They were descriptive in the sense that it had become uncertain when the medical diagnosis of death could be pronounced; but they were also moral in the sense that it was uncertain how people whose death could not be determinately pronounced should be treated. These two types of uncertainty were, moreover, connected, as the medical diagnosis of death was generally believed to have consequences for both the proper (moral) treatment of people and the (moral) question of whether transplantation was allowed or not. At least three sources of uncertainty were involved: first, the question whether a patient in a (seemingly) irreversible coma should be kept 'alive' (with mechanical ventilation); second, the question of the (uncertain) meaning of a flat EEG; and third, the question of organ transplantation. A flat EEG was often seen as a predictor of non-survival, and transplantation was only permitted if a clear and uncontroversial determination could be made that a person was in fact dead.

As the search for moral authority and the associated news reports show, moral uncertainty and moral inquiry are interrelated. In a way that is characteristic of moral uncertainty, as people struggled with the practical question of what to do with comatose and unresponsive patients, they also undertook inquiry into new concepts and values for interpreting their 
experiences. Different inquiries focused on different aspects, and different people perceived the relation between the mentioned issues differently. Beecher, who eventually chaired the Harvard committee, was mainly concerned about what Belkin (2002, vol. 58) calls "bedside concerns" about how to deal with patients in a (seemingly) irreversible coma. Schwab, a neurologist on the committee, had a long-standing interest in the "physiological parameters of the definition of death" (Belkin 2002, 58:332). As early as 1941, he carried out EEG measurements of a patient in the emergency ward and concluded from this experience that the electrocardiogram is a better indicator than the heartbeat of the exact time of death (Ibid., 58:332-333). Indeed, a larger community of neuroscientific researchers became convinced in the next two decades of the relation between EEG measurements and consciousness (Ibid., 58:333-340). However, the implications of these insights for bedside considerations were not obvious (lbid., 58:340).

Meanwhile, similar issues were debated by transplant surgeons. Giacomini describes the 1966 Ciba Foundation symposium as "[p]robably the most thorough interdisciplinary scrutiny of death" $(1997,44: 1467)$. At the meeting, there was no agreement on whether death should be redefined, and, if so, what the signs of death should be, and some warned that death should not be redefined for the sole purpose of facilitating transplantation.

The various lines of inquiry came together in the deliberations of the Harvard committee (see Belkin 2002, vol. 58, Giacomini 1997, vol. 44). For example, there was a debate about whether the committee should propose criteria for irreversible coma, criteria for brain death, or simply a redefinition of death. Another important point of discussion was the relation of these issues to transplantation. Although the committee was careful to avoid any suggestion that the formulation of criteria was motivated by transplantation concerns, it is clear that some committee members linked both issues and wanted criteria that would not impede the development of transplantation.

The criteria eventually formulated by the committee quickly became authoritative and more or less broadly accepted, although that certainly does not mean that they were uncontroversial. They have been (heavily) criticized for being motivated too much by utilitarian concerns for transplantation, as well as for being philosophically and ethically shallow where it comes to the understanding of 'death' and its moral implications.

\section{Discussion}

As we have used the terms, moral uncertainty starts as an individual phenomenon and is about being uncertain, confused or perplexed about what values and norms to apply or how to apply them. Groups can be said to be morally uncertain when their members are individually or mutually uncertain. Moral inquiry is the attempt to respond to such uncertainty by looking for new values and concepts. Although it may manifest itself individually, it is typically collective in nature as it is aimed at (re)establishing community consensus on how to deal with a certain moral issue. Both uncertainty and inquiry are epistemic in the sense that they depend on the possibility of knowledge and consensual resolution of moral questions. Moral inquiry is distinct from mere disagreement or controversy in that it depends on the ongoing existence of a conversation or community discourse in which consensus remains a possible outcome. As we use the term "inquiry," it can be traced to Dewey's pragmatism (1939). 
It is not difficult to find evidence of moral uncertainty and inquiry in these cases, but how does this help explain the disruptive nature of technomoral change, bridging the explanatory gap? In this section we highlight some key features of the cases and conclude with a sketch of a revised theory of technomoral change and disruption, and some suggestions for followup research.

The first key feature is that moral uncertainty in these cases is a broader and more open phenomenon than has been described in the philosophical literature. Lockhart (2000) defines moral uncertainty as a situation in which it is not known how one ought to act, because different moral theories recommend different courses of action and it is not known which of them is correct. That kind of moral uncertainty cannot be observed in these cases. Even in the most "intellectual" of the cases, the brain death case, there is no reference to moral theories. Instead, the conversation oscillates between different ways of conceptualizing death. Ethical concepts are part of this discussion, but even more prominent are interpretive questions of how to classify cases of what came to be called "brain death". For this reason, even a broader definition of moral uncertainty as uncertainty about what ought to be done that remains after the empirical facts have been fixed (as in Bykvist 2017), does not sufficiently encompass these cases. Moral uncertainty has more to do with how people interpret their situation - what moral attitudes, concepts, and emotions are appropriate - than with questions that treat certain theoretical or conceptual options as fixed in advance. Moral uncertainty cannot easily be separated from factual uncertainty, and there are important relationships between the two. When it becomes uncertain whether a person on mechanical ventilation is dead, for example - and when it is also unclear whether our conceptual distinction of dead/ alive is sufficient to cover such a case descriptive or interpretive uncertainty implies moral uncertainty as well. Disagreement over the applicability of thick moral concepts, such as "dead", is an element of moral disruption in the cases we have considered. This complicates social discourse because different parties have a different moral understanding of both world and word, and talk past one another. Reconciliation is difficult and can sometimes only be achieved through conceptual invention (e.g., "brain death"). When these conceptual inventions are successful and widespread, they are like the paradigm shifts of Baker's (2019) moral revolutions (see Section II above).

The second key feature is about the who and what of moral uncertainty. In section II, we set the aim of showing how properties of the technologies and the social context create what might be called "differential disruption." The institutional control over these different technologies and the expertise required to use them, as well as their different reception by those with different group affiliations and identies, had knock-on effects regarding what moral questions thereby arose, and for whom. One can easily imagine that the unit cost of each technology was also a factor in explaining who could meaningfully consider using it. In these cases, moral uncertainty is experienced in the first instance by users and prospective users of the technology, who need to decide whether and how to use the technology, whether it be the EPT, the pill, or the mechanical ventilator. This encompasses both lay and professional users of the technology. Clinicians had to decide when to offer the EPT and the pill to women and couples, and when to apply mechanical ventilation to patients. At the same time, women and couples had to decide whether to actively seek the EPT and the pill, whereas there is no evidence that patients were in a position to actively seek mechanical ventilation. Professional users were often concerned with standard-setting. Their inquiries aim to settle issues of authority ("Who has discretion?") and policy. In these ways, for different people (married, unmarried, adolescent, professional, black, white, Catholic), moral 
uncertainty took different questions as its object. In the three cases examined here, as one moves further away from users of the technology, one observes political controversy and position-taking, rather than an attempt to resolve a question about what to do. Some forms of controversy do not count as moral inquiry as we understand it, because they are based on fixed positions and are not open to shared resolution. Whereas for individual users the salient issues are varied and situation-dependent, in the mainstream public controversy a few main issues come to seem decisive.

The third key feature of these cases concerns when moral uncertainty and inquiry are observed in the process of technomoral change. The historical record of uncertainty and inquiry begins well after the original development and public introduction of these technologies, with a gap of up to several years. Perhaps more surprisingly, in these cases the record of moral uncertainty and inquiry eventually end, even if the mainstream public controversy lives on. On the one hand, this could be because particular populations actually resolve the moral questions at stake for themselves in a new way. On the other hand, it could be that the issues and positions at stake become politicized in a way that swamps the experience of individual moral uncertainty and crowds out the process of inquiry.

We now move away from the details of the cases to sum up the main points of the revised theory of technomoral change in terms of moral uncertainty and moral inquiry. The first point is about the conception of moral disruption that emerges: it is understood as the process of attempting to close an interpretive and conceptual gap, so as to make sense of one's experiences and choices in a way that is understood and shared by others in the moral community. This complements what Swierstra et al. (2009) call "hot" ethical discourse, consisting of controversies and power struggles. Technomoral change is disruptive, not just because it is hot, but because it is personal, hazardous, and resource-intensive. As we have seen, (potential) users have a personal stake in the resolution of moral uncertainty surrounding new technologies. Yet the process can result in failure, either in the sense that others in the discussion are not brought to agree with any of the proffered concepts or reinterpretations, or in the sense that the broader public does not understand or approve. This is therefore a personal hazard. Moreover, it requires resources that are not readily available, calling upon the moral imagination of those affected and requiring an effort, through inquiry, to articulate their imagination to others, and for others to listen. People need to go out on a limb to engage in this type of inquiry. Because of the personal hazards involved, uncertainty is experienced as distressing to individuals (cf. Nickel 2020). This distress is the phenomenological core of technomoral disruption. ${ }^{9}$

The second point concerns the explanation of how moral uncertainty is resolved, leading to a new set of "moral routines." Following the pragmatists, we see that the process of inquiry is a response to the distress of moral uncertainty. ${ }^{10}$ According to Dewey (1922), moral

\footnotetext{
${ }^{9}$ By comparison, Swierstra et al. (2009) envision moral imagination as a research method in scenario building, rather than an ordinary response to the distress of uncertainty.

${ }^{10}$ C.S. Peirce writes that "the irritation of doubt is the only immediate motive for the struggle to attain belief. I shall term this struggle Inquiry..." (Buchler 1955, p. 10). Similarly, Dewey writes "... valuation takes place only when there is something the matter; when there is some trouble to be done away with, some need, lack, or privation to be made good, some conflict of tendencies to be resolved by means of changing existing conditions. This fact in turns proves that there is present an intellectual factor - a factor of inquiry - whenever there is valuation" (ToV, 34).
} 
inquiry allows one to ameliorate such distress by revising the moral commitments one has to "fit" the uncertain, problematic situation at hand. A collective fitting of existing moral routines with the present disruptive situation resembles a process of moral hermeneutics, whereby the existing moral routines become visible and undergo change to offer a better coordinated response to the present situation. The individual and collective past experiences work as a basis for revising moral routines until they achieve an appropriate response to the uncertainty the present situation invokes. In such a way, even though moral inquiry may not always resolve the problematic situation, it may fit it within the moral routines by reinterpreting them.

Although the NEST-ethics account of technomoral change also makes the disruption of moral routines a cornerstone of change, it does not offer a full explanation of how the disruption proceeds and resolves. Moral inquiry fills this gap; it may be understood as a guided search process that may eventually result in moral change if, through inquiry, a new routine, response or rule is found that resolves the moral uncertainty. It is a search process because the inquirer does not know beforehand what will work to solve the moral quandary. Indeed, we see in our cases that people in moral uncertainty try out different answers and different courses of action, sometimes successfully, other times less successfully. However, inquiry is not just a matter of trial-and-error; it is guided in the sense that people intelligently try out responses to new instances of moral uncertainty. This guidance may come from existing past moral responses and routines, reinterpreted in the new situation, but also from people reasoning about the newly arisen moral dilemmas or using their moral imagination (Chappell 2014).

While inquiry often seems to start individually, it is a collective or communal activity whose success in overcoming initial uncertainty requires the relevant social group, or groups, to accept it as a solution to the initial moral unease. This social dimension is underemphasized in Baker's (2019) agent-driven account of moral revolutions, discussed in section II. Unsurprisingly, there is often disagreement or even controversy over what works as a solution to the moral uncertainty that sparked the inquiry. We see this clearly in the cases we have discussed. This may explain why these cases have sometimes been interpreted as just the outcome of a power struggle or a clash of interests (as in the case of brain death). Such interpretations only tell part of the story, however. What they miss is that inquiry is a collective hermeneutic and deliberative search process, bound by what actually helps to eventually overcome the stress of moral uncertainty, in both practical and experiential senses. ${ }^{11}$

This revised theory helps us understand the dynamics of moral change and disruption, adding depth and complexity to our understanding of technomoral change. It provides additional conceptual resources to explain why some instances of technomoral change are disruptive without resulting in much public controversy, whereas others result in something more akin to moral revolution. By observing the different moral questions that arise for different (prospective) users in relation to their access to and control of the applications of the technology, it points toward a more fine-grained understanding of how social and

\footnotetext{
11 In earlier work, Baker (2002) makes an analogous point against "historicists" who interpret the development of bioethics as merely the outcome of a contest for professional control of medical research. Baker (2013) presents a view of the development of medical ethics based on social moral norms, from which his later theory of moral revolutions appears to diverge.
} 
technological factors create moral disruption and controversy ("differential disruption"). Furthermore, by drawing our attention to the personal distress of moral disruption and the social processes by which this distress is resolved, it suggests new avenues of psychological and sociological study that are strongly linked with anticipatory ethics of technology.

Some may worry that the view presented here is overly epistemic with its emphasis on uncertainty and inquiry. They may, for example, worry that it can only account for changes in moral beliefs, and not for changes in moral behavior, routines or procedures. We believe that such a worry is mistaken. The point is that whenever moral behaviour, routines and procedures are disrupted there is always a moment of moral uncertainty, often manifested as unease or perplexity (and not necessarily solely in explicitly cognitive terms) and there will be inquiry, because, as Dewey says, such unease will trigger evaluation even if previously moral behaviour and routines were taken for granted and unreflective.

Another worry might be that our account neglects power differences and power struggles in moral disruption. However, we by no means pretend that such power differences or power struggles are irrelevant, but only that they are not the full story and do not constitute disruption in themselves. Power struggles over new technologies often do not result in moral disruption. For example, software to evade emissions testing in the automotive industry has repeatedly been attended by power struggles regarding an innovative technology, but it created widespread moral indignation rather than moral uncertainty, and therefore lacks the hallmarks of moral disruption. Properly understanding the role of power differences requires attention to the epistemic dimension, as it emphasizes the fact that people in different positions may experience moral uncertainty quite differently. Power struggles often have an epistemic dimension and cannot be properly understood without taking into account that dimension. What is at stake often are not just conflicting interests but conflicting epistemic points of view, understood as a shared struggle to make sense of experience and justify action and collective endeavors.

One of the open questions our account leaves is how we can best anticipate the disruption of technomoral change. The distress and perplexity experienced by individuals in response to the issues raised by new technologies are distinct from the "moral controversies" that Swierstra et al. argue we should try to anticipate $(2009,121)$. When they then argue that anticipating technomoral change is a matter of providing "training" to citizens to "accept, and learn to deal with" this fundamental feature of modernity (ibid.), the true nature of technomoral change is clearly of decisive importance. We hope to have made a contribution to understanding the underlying phenomena of moral uncertainty and inquiry, but perhaps more importantly, we hope that they are placed higher on the agenda of those concerned with anticipatory ethics.

A task for the future is to document and explain other varieties of technomoral disruption. The cases we have considered in this paper lie in a narrow band, both historically and thematically, and this may be artificially restrictive. One of the most salient disruptive technologies of the present era, social media, appears to cause moral disruption not by prompting moral uncertainty and inquiry, but rather by circumventing it. It divides society into groups of people that talk to one another within, but not across those groups. Across groups, people engage in ideological clashes and disagreement, but not shared discourse or inquiry. Each group's values, norms, and even its understanding of the facts are not shared with that 
of other groups. If this interpretation is correct, then moral disruption can also be a matter of short-circuiting normal processes of moral uncertainty and inquiry. This illustrates that there may be other kinds of technomoral disruption under the sun.

\section{References}

Ad Hoc Committee of the Harvard Medical School to Examine the Definition of Brain Death. 1968. "A Definition of Irreversible Coma: Report of the Ad Hoc Committee of the Harvard Medical School to Examine the Definition of Brain Death." JAMA 205:337-340.

Appiah, Kwame Anthony. 2010.The Honor Code: How Moral Revolutions Happen. New York and London: WW Norton \& Company.

Arnaldi, Simone. 2018. "Retooling Techno-Moral Scenarios. A Revisited Technique for Exploring Alternative Regimes of Responsibility for Human Enhancement." Nanoethics 12:283-300.

Baker, Robert. 2002. "Bioethics and History." Journal of Medicine and Philosophy 27: 447-474.

Baker, Robert. 2013. Before Bioethics. Oxford University Press.

Baker, Robert. 2019. The Structure of Moral Revolutions: Studies of Changes in the Morality of Abortion, Death, and the Bioethics Revolution. Cambridge, MA: The MIT Press.

Belkin, Gary S. 2003. "Brain Death and the Historical Understanding of Bioethics." Journal of the History of Medicine and Allied Sciences 58:325-361.

Bicchieri, Cristina. 2005. The Grammar of Society: The Nature and Dynamics of Social Norms Cambridge University Press.

Buchler, Justus. Editor. 1955. Philosophical Writings of Peirce. New York: Dover Publications, Inc.

Bykvist, Krister. 2017. "Moral Uncertainty." Philosophy Compass 12:e12408.

Chappell, Timothy. 2014. Knowing What to Do: Imagination, Virtue, and Platonism in Ethics. Oxford University Press.

Cvetkovich, George, Barbara Grote, Ann Bjorseth, and Julia Sarkissian. 1975. "On the psychology of adolescents' use of contraceptives." The Journal of Sex Research 11:256-270.

Dewey, John. 1922. Human Nature and Conduct: An Introduction to Social Psychology. New York: Holt.

Dewey, John. 1939. Theory of Valuation. Chicago: The University of Chicago Press. 
Entwistle, P. A. 1976. "Do-It-Yourself Pregnancy Tests: The Tip of the Iceberg?" American Journal of Public Health 66:1108-1109.

Farnsworth, Dana L. 1965. "Sexual Morality and the Dilemma of the Colleges." American Journal of Orthopsychiatry 35:676-681.

Fricker, Miranda. 2007. Epistemic Injustice: Power and the Ethics of Knowing. Oxford, UK: Oxford University Press.

Feldman, Eli. 1969. "The Sexual Revolution.” Journal of Contemporary Psychotherapy 2:54-56.

Giacomini, Mita. 1997. "A Change of Heart and a Change of Mind? Technology and the Redefinition of Death in 1968." Social Science \& Medicine 44:1465-1482.

Greeley, Andrew. 1973. "The Sexual Revolution Among Catholic Clergy." Review of Religious Research 14:91-100.

Hermann, Julia. 2019. “The Dynamics of Moral Progress.” Ratio 32:300-311.

Ketting, Evert. 2000. "De Invloed van Orale Anticonceptie op de Maatschappij." Nederlands Tijdschrift voor Geneeskunde 144:283-286.

Keulartz, Jozef, Michiel Korthals, Maartje Schermer, and Tsjalling Swierstra. 2002. "Ethics in a Technological Culture. A Proposal for a Pragmatist Approach." Pp. 3-21 in Pragmatist Ethics for a Technological Culture. Edited by Jozef Keulartz, Michiel Korthals, Maartje Schermer and Tsjalling Swierstra. Dordrecht: Kluwer Academic Publishers.

Kudina, Olya and Peter-Paul Verbeek. 2019. "Ethics From Within: Google Glass, the Collingridge Dilemma, and the Mediated Value of Privacy." Science, Technology, \& Human Values 44:291-314.

Kudina, Olya. 2019. "Accounting for the Moral Significance of Technology: Revisiting the Case of Non-Medical Sex Selection." Journal of bioethical inquiry 16:75-85.

Kuhn, Thomas. 1962. The Structure of Scientific Revolutions, 2nd Edn. Chicago: University of Chicago Press.

Leavitt, Sarah A. 2006. "'A Private Little Revolution': The Home Pregnancy Test in American Culture." Bulletin of the History of Medicine 80:317-345.

Lockhart, Ted. 2000. Moral Uncertainty and its Consequences. Oxford, UK: Oxford University Press.

Machado, Calixto. 2007. Brain Death: A Reappraisal. New York: Springer.

Machado, Calixto, J. Korein, Y. Ferrer, L. Portela, M. de la C. García, M. Chinchilla, Y. Machado, Y. Machado, and J. M. Manero. 2007. "The Declaration of Sydney on Human Death." Journal of Medical Ethics 33:699-703. 
Marsh, Margaret, and Wanda Ronner. 2008. The Fertility Doctor: John Rock and the Reproductive Revolution. Baltimore: Johns Hopkins University Press.

Martin, John Levi. 1996. "Structuring the Sexual Revolution." Theory and Society 25:105-151.

McAdams, Richard H. 1997. "The Origin, Development, and Regulation of Norms." Michigan Law Review 96:338-433.

McCance, Colin and Don J. Hall. 1972. "Sexual Behaviour and Contraceptive Practice of Unmarried Female Undergraduates at Aberdeen University." British Medical Journal 2:694-700.

National Institutes of Health. 2020. "The Thin Blue Line. The History of the Pregnancy Test." Available at: https://history.nih.gov/display/history/Pregnancy+Test++ A+Thin+Blue+Line+The+History+of+the+Pregnancy+Test. Accessed on June 22, 2020.

Nickel, Philip J. 2020. Disruptive innovation and moral uncertainty. Nanoethics. DOI: 10.1007/s11569-020-00375-3.

Parry, Manon. 2013. Broadcasting Birth Control: Mass Media and Family Planning. Rutgers University Press.

Randall, Harriett B. 1969. "Talking Upstairs.” Journal of School Health 39:150-153.

Reed, James. 1978. The Birth Control Movement and American Society: From Private Vice to Public Virtue. Princeton University Press.

Schadler, Cornelia. 2013. Key Practices of the Transition to Parenthood. Current Sociology 62:114-131.

Swierstra, Tsjalling. 2013. "Nanotechnology and Technomoral Change." Etica \& Politica / Ethics \& Politics 15:200-219.

Swierstra, Tsjalling, Dirk Stemerding and Marianne Boenink. 2009. "Exploring TechnoMoral Change: The Case of the Obesitypill." Pp. 119-138 in Evaluating New Technologies. Edited by Paul Sollie and Marcus Duwell. Springer: Dordrecht.

Wright, David, Rachel Finn, Raphael Gellert, Serge Gutwirth, Philip Schütz, Michael Friedewald, Silvia Venier, and Emilio Mordini. 2014. "Ethical Dilemma Scenarios and Emerging Technologies." Technological Forecasting and Social Change 87:325-336. 